\title{
Changing, Priming, and Acting on Values: Effects via Motivational Relations in a Circular Model
}

\author{
Gregory R. Maio \\ Cardiff University \\ Wing-Yee Cheung
Cardiff University
}

\author{
Ali Pakizeh \\ Persian Gulf University
}

Kerry J. Rees

University of Gloucestershire

\begin{abstract}
Circular models of values and goals suggest that some motivational aims are consistent with each other, some oppose each other, and others are orthogonal to each other. The present experiments tested this idea explicitly by examining how value confrontation and priming methods influence values and valueconsistent behaviors throughout the entire value system. Experiment 1 revealed that change in 1 set of social values causes motivationally compatible values to increase in importance, whereas motivationally incompatible values decrease in importance and orthogonal values remain the same. Experiment 2 found that priming security values reduced the better-than-average effect, but priming stimulation values increased it. Similarly, Experiments 3 and 4 found that priming security values increased cleanliness and decreased curiosity behaviors, whereas priming self-direction values decreased cleanliness and increased curiosity behaviors. Experiment 5 found that priming achievement values increased success at puzzle completion and decreased helpfulness to an experimenter, whereas priming with benevolence values decreased success and increased helpfulness. These results highlight the importance of circular models describing motivational interconnections between values and personal goals.
\end{abstract}

Keywords: priming, motivation, goals, behavior

Specific patterns of motivation interconnection have been described in an influential model of social values (Schwartz, 1992) and a more recent model of personal goals (Grouzet et al., 2005). The model of values focuses on abstract ideals - such as freedom, equality, helpfulness, and enjoying life - that people regard as important guiding principles. The model of personal goals focuses on aims and aspirations-such as self-acceptance, affiliation, physical health, and popularity - that a person has. Despite their slightly different foci, both models propose that there are "four occasionally overlapping but sometimes conflictual motivational systems that people must negotiate as they make their way through life" (Grouzet et al., 2005, p. 813). In this article, we briefly review these models and argue that their assumptions about motivational interconnections can be useful for understanding basic mechanisms in judgment and action. This idea is then illustrated in five experiments that explore novel implications derived from one of the models.

Gregory R. Maio and Wing-Yee Cheung, School of Psychology, Cardiff University, Cardiff, Wales, United Kingdom; Ali Pakizeh, Department of Psychology, Persian Gulf University, Boushehr, Iran; Kerry J. Rees, School of Psychology, University of Gloucestershire, Cheltenham, United Kingdom.

We thank Tim Kasser, Russell Spears, and Geoff Haddock for their comments on prior versions of the article.

Correspondence concerning this article should be addressed to Gregory R. Maio, School of Psychology, 70 Park Place, Cardiff University, Cardiff, Wales, United Kingdom CF10 3AT. E-mail: maio@cardiff.ac.uk

\section{CIRCULAR PATTERNS IN VALUES AND PERSONAL GOALS}

Schwartz's (1996) cross-cultural model of values indicates that values are self-imposed criteria that balance between individual needs, the coordination of social interaction, and group survival. As values coordinate these concerns, they come to express and serve 10 types of motivation: power, achievement, hedonism, stimulation, self-direction, universalism, benevolence, tradition, conformity, and security (see Table 1 for more detail). ${ }^{1}$ More important, Schwartz (1992) suggested that these 10 motives possess various conflicts and compatibilities. As shown in Figure 1, these motivational interconnections can be modeled in a circular structure. In this structure, values that express compatible motives are adjacent to each other, whereas values that express conflicting motives are opposite each other. The structure yields two dimensions underlying four broad, higher order types of values, which reflect motivational orientations that encompass the 10 lower order motives. One dimension contrasts self-enhancement values, which promote self-interest (e.g., wealth, ambition), with selftranscendence values, which transcend personal interest to consider the welfare of others (e.g., helpfulness, equality). The other dimension contrasts conservation values, which protect the status quo (e.g., family security, social order), with openness values,

\footnotetext{
${ }^{1}$ The capacity of values to both organize and express goals is consistent with evidence that values both direct and justify judgment and action, depending on the context (Eiser, 1987; Kristiansen \& Zanna, 1988).
} 
Table 1

Schwartz's (1992) 10 Value Types and Their Principal Value Labels

\begin{tabular}{|c|c|c|}
\hline Value type & Definition & Value labels \\
\hline Power & $\begin{array}{l}\text { Social status and prestige, control or dominance over people } \\
\text { and resources }\end{array}$ & Social power, wealth, authority, preserving my public image \\
\hline Achievement & $\begin{array}{l}\text { Personal success through demonstrating competence according } \\
\text { to social standards }\end{array}$ & Successful, ambitious, capable, influential \\
\hline Hedonism & Pleasure and sensuous gratification for oneself & Pleasure, enjoying life \\
\hline Stimulation & Excitement, novelty, and challenge in life & A varied life, daring, an exciting life \\
\hline Self-direction & Independent thought and action-choosing, creating, exploring & $\begin{array}{l}\text { Creativity, freedom, independent, curious, choosing own } \\
\text { goals }\end{array}$ \\
\hline Universalism & $\begin{array}{l}\text { Understanding, appreciation, tolerance, and protection for the } \\
\text { welfare of all }\end{array}$ & $\begin{array}{l}\text { Broadminded, wisdom, a world of beauty, equality, unity } \\
\text { with nature, a world at peace, social justice, protecting the } \\
\text { environment }\end{array}$ \\
\hline Benevolence & $\begin{array}{l}\text { Preservation and enhancement of the welfare of people with } \\
\text { whom one is in frequent personal contact }\end{array}$ & Honest, loyal, helpful, forgiving, responsible \\
\hline Tradition & $\begin{array}{l}\text { Respect, commitment, and acceptance of the customs and ideas } \\
\text { that traditional culture or religion provide the self }\end{array}$ & $\begin{array}{l}\text { Respect for tradition, humble, accepting my portion in life, } \\
\text { devout, moderate }\end{array}$ \\
\hline Conformity & $\begin{array}{l}\text { Restraint of actions, inclinations, and impulses likely to upset } \\
\text { or harm others and violate social expectations or norms }\end{array}$ & $\begin{array}{l}\text { Self-discipline, obedient, politeness, honoring of parents and } \\
\text { elders }\end{array}$ \\
\hline Security & Safety, harmony, and stability of society, relationships, and self & $\begin{array}{l}\text { Family security, national security, reciprocation of favors, } \\
\text { social order, clean }\end{array}$ \\
\hline
\end{tabular}

which follow intellectual and emotional pursuits in uncertain directions (e.g., creativity, curiosity).

The circular model has been supported in studies of over 200 samples from more than 70 countries (Schwartz \& Rubel, 2005). Most of these studies analyzed participants' responses to the Schwartz (1992) Value Survey, which asks respondents to rate the importance of 56 values (e.g., freedom) with a 9-point unipolar scale. Results revealed that the values cohered well within each of the 10 motivation types (e.g., security, benevolence), forming reliable scales in aggregate measures of each motivational type. More important, patterns of correlations between individual values were consistent with the circular model. That is, adjacent values

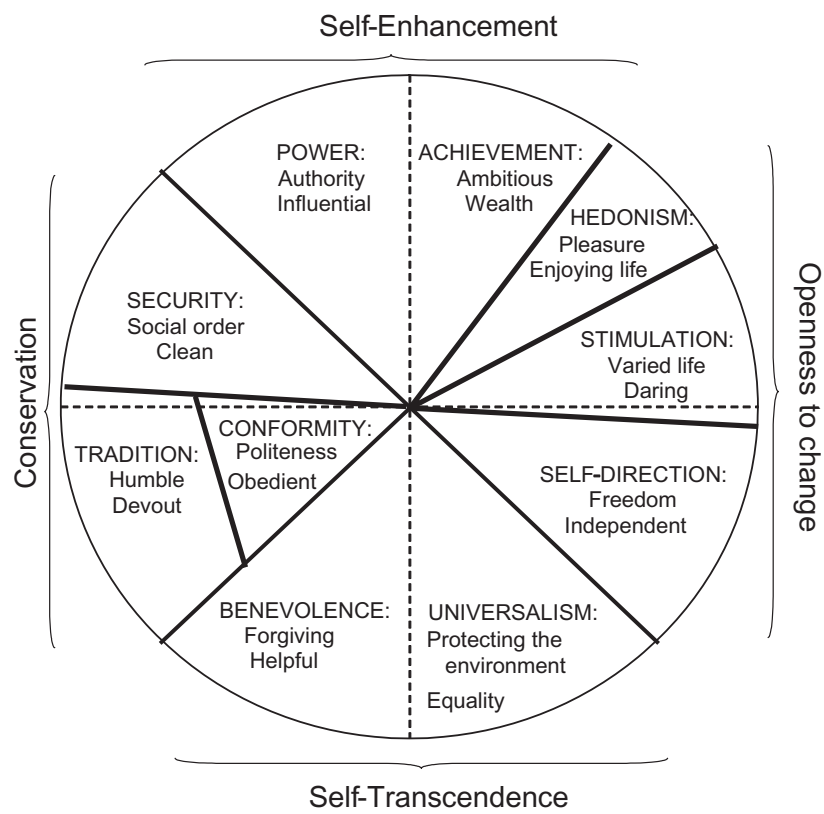

Figure 1. Schwartz's (1992) circular model of social values. tended to be positively correlated, and values at about 90 degrees tended to have less positive or null correlations, whereas ratings of opposing values tended to have null or negative relations, and the ordering of the values in a two-dimensional map of value interrelations was consistent with the model (Schwartz, 1992). In addition, the model successfully predicts patterns in value-relevant reasoning (Bernard, Maio, \& Olson, 2003a, 2003b), the speed of value rating (Pakizeh, Gebauer, \& Maio, 2007), value-behavior relations (Bardi \& Schwartz, 2003; Garling, 1999; Judge \& Bretz, 1992), and the relations between values and other constructs (Roccas, Sagiv, Schwartz, \& Knafo, 2002; Sagiv \& Schwartz, 1995; Schwartz, 1992). These correlations often follow a sinusoidal wave form across the 10 values around the circle (e.g., Kasser, Koestner, \& Lekes, 2002). For instance, Sagiv and Schwartz (1995) found that readiness for contact with a dominant outgroup was positively related to self-direction and universalism values and was negatively related to opposing conformity, tradition, and security values. Similarly, Roccas et al. (2002) found that the pattern of correlations between values and several dimensions of personality was consistent with the circular model, such that opposing value domains tended to have opposite directions of correlation with particular traits (e.g., extroversion).

It is interesting that Grouzet et al.'s (2005) analysis of personal goals and aspirations yielded a similar set of results. This model built on a theoretical distinction between intrinsic and extrinsic goals derived from self-determination theory (Deci \& Ryan, 2000; Kasser \& Ryan, 1996). Intrinsic goals fulfill psychological needs for relatedness, autonomy, and competence and are inherently satisfying to pursue. In contrast, extrinsic goals focus on obtaining rewards or social praise and tend to be less inherently satisfying. Grouzet et al. proposed four basic intrinsic goals (self-acceptance, affiliation, community feeling, and physical health) and three basic extrinsic goals (financial success, image, and popularity). In addition, they suggested that these goals combine with four additional goals (conformity, safety, hedonism, and spirituality) to yield two dimensions of goal pursuit. One dimension ranges from intrinsic to 
extrinsic goals, and the second dimension ranges from physical to self-transcendent goals.

The hypothesized compatibilities and conflicts between personal goals in these higher order domains were supported by Grouzet et al.'s (2005) research in 15 countries. This research analyzed participants' responses to an extended version of Kasser and Ryan's (1996) Aspiration Index, which asks respondents to rate the importance of 57 "goals that you may have for the future" (Grouzet et al., 2005, p. 803; e.g., "I will have a committed, intimate relationship") with a 9-point unipolar scale. Results revealed patterns of correlations between personal goals that were consistent with the circular model. That is, adjacent goals tended to be positively correlated, whereas ratings of orthogonal goals tended to exhibit null relations and opposing goals tended to exhibit negative relations. Overall, the pattern of goal interrelations was consistent with the two dimensions proposed by the model.

Despite differences in the circular models' dimensions (e.g., intrinsic-extrinsic vs. conservation-openness) and focus (i.e., broad social ideals vs. personal goals and aspirations), it is interesting and important that both of these separate models have yielded two dimensions of motivational conflict and compatibility. Due to this common perspective, each model provides a powerful conceptual basis for a priori predictions about the effects of changing specific values or personal goals and of priming specific values or personal goals. The circular models indicate that each type of intervention should have consequences that go beyond the effects on the specific values or personal goals that have been changed or primed, because of the impact of these interventions on underlying motivational tensions that connect the values or personal goals. That is, the models propose important motivational dynamics and not merely a psychometric pattern. The potential importance of these motivational processes is the basis for the present research.

To begin to reveal these processes, we have chosen to focus on the latent motivational interconnections implied by Schwartz's (1992) model of values, which has received more direct tests thus far. Specifically, the present research attempted to show how the model has novel implications for understanding effects of value change and effects of value priming. The discovery of systemic effects in value change and value priming would provide a vital first step toward revealing the importance of conflicts and compatibilities between basic motivations. Moreover, systemic effects of value change and value priming would have important theoretical and applied ramifications in their own right, as we describe later in this article.

\section{MOTIVATIONAL TENSIONS AND VALUE CHANGE}

Consider first the potential effects of changing values. If values are related through the motives that they serve, then changing a value should cause changes throughout the whole system. Values that serve the same motives as a promoted value should increase in importance, whereas values that serve conflicting motives should decrease in importance. For example, if the value of equality expresses a universalist motive, as predicted by the circular model of values, then any event that causes individuals to increase the importance of equality should cause them to increase the importance of other values that similarly promote universalism (e.g., a world at peace). At the same time, such an event should decrease the importance of values (e.g., wealth) that express opposing motives, such as power and achievement and have no effect on values promoting orthogonal motives (e.g., politeness). To take a different example, if the value of freedom expresses a selfdirection motive, as predicted by the circular model, then any event that increases the importance of freedom should cause an increase in the importance of other values that express the same motive (e.g., creativity). In addition, there should be a decrease in the importance of values (e.g., cleanliness) that express opposing aims, such as conformity, and no effect on values serving orthogonal motives (e.g., achievement).

These predictions are powerful, because they involve wideranging effects of value changes based on the notion of compatibilities and conflicts between underlying motives. The most relevant research has used Rokeach's $(1973,1975)$ well-known value self-confrontation procedure to examine value change experimentally. In this procedure, participants receive feedback that makes them feel dissatisfied with the extent to which one of their values fulfills their self-conceptions of competence or morality (Grube, Mayton, \& Ball-Rokeach, 1994; Rokeach, 1975), and they reduce this self-dissatisfaction by changing their value priorities. Numerous experiments have used the value self-confrontation procedure to modify values, attitudes, and behavior that are often regarded as being resistant to change (Chernoff \& Davison, 1999; Devine, Plant, \& Buswell, 2000; Grube, Chen, Madden, \& Morgan, 1995; Grube et al., 1994; Schwartz \& Inbar Saban, 1988). Thus, this procedure has become an important intervention and object of study (see Devine et al., 2000; Grube et al., 1994).

An important unresolved issue, however, is whether value selfconfrontation also causes people to change values other than those targeted in the procedure. In the typical use of this paradigm, individuals receive feedback emphasizing a deficiency in the extent to which they possess a specific value, and they respond by increasing the importance of the "deficient" value. Rokeach (1973) suggested that there should also be patterns of change in nontargeted values, but his model did not enable a priori predictions of patterns of change. The circular models raise the possibility that value self-confrontation may increase the importance of different unmentioned values that serve the same underlying motive as does the target value, decrease the importance of unmentioned values that serve an opposing motive, and have no effect on the importance of unmentioned values that serve an orthogonal motive. This focus on unmentioned values is crucial, because any systematic effects on these values would provide a clear indication of a latent motivational structure. If values reflect a motivational system, then altering some of the values should promote some motives and diminish the importance of others, causing predictable changes across the values.

To our knowledge, this systemic implication of value change has never been tested. This implication can be examined through an experiment that asks participants to judge the importance of diverse self-transcendence, self-enhancement, openness, and conservation values before and after a manipulation that varies which of these types of values is targeted through a value selfconfrontation procedure. This procedure would enable direct tests of four key predictions. First, value self-confrontation support for a specific set of self-transcendence values should increase the importance of other (different) self-transcendence values, decrease the importance of self-enhancement values, and have no effect on 
openness and conservation values. Second, value selfconfrontation support for specific self-enhancement values should increase the importance of other self-enhancement values, decrease the importance of self-transcendence values, and have no effect on openness and conservation values. Third, value selfconfrontation support for specific openness values should increase the importance of other openness values, decrease the importance of conservation values, and have no effect on self-transcendence and self-enhancement values. Fourth, value self-confrontation support for specific conservation values should increase the importance of other conservation values, decrease the importance of openness values, and have no effect on self-transcendence and self-enhancement values. Evidence supporting these four predictions would be provocative because the paradigm entails numerous changes in values that are not targeted by the manipulation. This pattern would go far beyond the prior evidence demonstrating changes in target values alone.

\section{MOTIVATIONAL TENSIONS AND VALUE PRIMING}

If the clear and complex pattern of value change is obtained, it would be interesting to also examine the potential effects of merely activating values from memory (rather than changing them). Merely activating a motive-relevant concept from memory (i.e., priming) can increase people's behavior in pursuit of the motive (e.g., Bargh, Gollwitzer, Lee-Chai, Barndollar, \& Trotschel, 2001; Hertel \& Kerr, 2001; Macrae \& Johnston, 1998). For example, Bargh et al. (2001) found that priming participants with compete, succeed, and achieve caused them to better succeed at a subsequent word search task than when primed with neutral terms. Similarly, Macrae and Johnston (1998) found that participants who were primed with helpfulness were more likely to offer aid to an experimenter following a minor lab accident, as long as the aid was easy to perform. In both experiments, the behaviors were chosen on the assumption that they would affirm the primed constructs, which also happen to be values described in Schwartz's (1992) model.

Yet, as noted by Bargh (2006), every promoted or primed motive may have both excitatory and inhibitory effects on diverse behaviors, and there is a need to understand which behaviors will be affected by each motive. For example, we know that priming money can decrease helpfulness (Vohs, Mead, \& Goode, 2006). To this point, however, research on priming has not identified a theory that can be used to give an a priori justification for treating different behaviors as outcomes that should be facilitated or inhibited by different primes. The application of the circular models can move researchers beyond intuitive guesses about how particular motives might affect attitudes and behavior; instead, these models provide a strong theoretical grounding for predicting which behaviors and attitudes will be affected by which motives. Indeed, Burgoyne and Lea (2006) noted that the effects of money on (decreased) helping in the experiments by Vohs et al. (2006) is consistent with Grouzet et al.'s (2005) evidence that money and a sense of community are personal goals that serve opposing motives in their circular model. Of particular relevance to the present research, this finding also fits the contrasting positions between the values of wealth and helpfulness in Schwartz's (1992) model of values.
We therefore wished to test whether the circular model of values successfully predicts diverse effects of value priming on action. According to the circular model, priming values should activate the compatibilities and conflicts within the whole system. The interconnections between motives expressed by values should cause the pursuit of values that serve the same motives to be enhanced, whereas the pursuit of values that serve opposing motives should be thwarted and the pursuit of values that serve orthogonal motives should be unaffected. Our research focused on the two most important effects in this pattern-the potentially significant effects on values serving compatible and opposite motives (i.e., ignoring the null effect prediction). For example, if a set of values (e.g., successful, capable) expresses an achievement motive, as predicted by the circular model, then any intervention that activates these values should promote achievement behavior (e.g., success at a puzzle), as in past findings (Bargh et al., 2001). At the same time, such an intervention should decrease the performance of behavior that serves opposing motives, such as benevolence toward others, because of the reciprocal latent connection between these motives predicted by the model (see Figure 1). According to the model, the activation of achievement-promoting values would introduce a self-enhancing motivational focus that subtracts from the motivational orientation underlying the opposing, benevolent values (e.g., helpfulness), which instead rely on a motivational focus that transcends the self. This would make people more likely to construe a subsequent behavioral opportunity in terms of an achievement motive and less likely to construe the behavior in terms of a benevolent motive.

The prior experiments examining the effects of priming abstract motivational concepts have not enabled tests of such reciprocal effects. Bargh et al. (2001) and Macrae and Johnston (1998), among others (Hertel \& Kerr, 2001; Karremans, 2007; Maio, Olson, Allen, \& Bernard, 2001), focused on the effects of primes on intuitively compatible behaviors. Building on the circular model of values, we can test not only whether value priming increases the likelihood of performing a behavior that supports the motive expressed by the values, but also whether the value primes simultaneously decrease behavior that supports an opposing motivation. For example, do achievement value primes facilitate success at word puzzles but inhibit the spontaneous assistance offered to another? At the same time, do benevolence value primes inhibit play at word puzzles but increase spontaneous assistance? These questions involve modeling opposing effects of a single prime on two behaviors and a more ambitious search for simultaneously opposing effects of different value primes on different types of relevant behavior.

It would be ideal for an experiment to focus on the latter, interaction hypothesis across the full range of values, if it were not for difficulties in trying to design and assess relevant overt behaviors across multiple values without introducing fatigue, order effects, construal problems (e.g., assimilation vs. contrast), and conflict among the behaviors. A more feasible approach is to conduct a series of experiments, with each one showing the predicted facilitating and opposing effects along a different value dimension. Together, such experiments would provide provocative support for the motivational compatibilities and conflicts predicted by the circular models. Such systemic effects would provide a significant extension of our knowledge about the operation of values in the elicitation of behavior. 


\section{THE PRESENT STUDY}

The extant models of compatibilities and conflicts between motives facilitate predictions about systemic effects that have not been explored in past research. In the present research we looked for systemic effects of values, using both a manipulation of value change (see Experiment 1) and manipulations of value priming (see Experiments 2, 3, 4, and 5). We predicted that (a) changing some specific values would both increase the importance of values that serve the same or similar motives and decrease the importance of values that serve opposing motives, and (b) priming some specific values would cause participants to exhibit both more behavior consistent with the primed values and less behavior consistent with the opposed values.

\section{Experiment 1}

Experiment 1 tested whether a value self-confrontation manipulation that promotes one set of values would cause changes in other values. More specifically, we predicted that on the basis of Schwartz's (1992) theory about the motives served by values, any changes in particular values would reverberate throughout the whole value system, causing motivationally congruent values to increase in importance, motivationally opposing values to decrease in importance, and motivationally orthogonal values to exhibit no change.

To test these hypotheses, we asked participants to rank the importance of diverse self-transcendence, self-enhancement, openness, and conservation values before and after a manipulation that promoted the importance of one of these types of values. This procedure entailed a large-scale factorial design (i.e., five conditions and four value types) with many participants, because the complex pattern of predictions required good statistical power. For example, we expected that prioritizing self-transcendence values would increase the importance of other self-transcendence values while decreasing the importance of self-enhancement values. In contrast, prioritizing self-enhancement values would increase the importance of other self-enhancement values while decreasing the importance of self-transcendence values. We expected no changes in openness to change and conservation values in the conditions that prioritized self-transcendence or selfenhancement values (because these values are orthogonal to the openness to change and conservation values).

Similar highly specific patterns were expected for the conditions that prioritize openness and conservation values. We expected that prioritizing openness values would increase the importance of other openness values while decreasing the importance of conservation values. In contrast, prioritizing conservation values would increase the importance of other conservation values while decreasing the importance of openness values. We expected no changes in self-transcendence and self-enhancement values in the conditions that prioritized the openness or conservation values (because these values are orthogonal to the self-transcendence and self-enhancement values).

\section{Method}

\section{Participants}

In this study, 175 Cardiff University students (139 female, 36 male) participated for course credit. Data from 9 participants were removed from the analyses because of suspicion.

\section{Procedure}

Participants were randomly assigned to either a control group or one of four experimental groups. Participants were tested individually and told that the session included several tasks, which they completed in the following order: a premanipulation measure of value importance, a manipulation of value self-confrontation feedback, and a postmanipulation measure of value importance. ${ }^{2}$ Participants were then probed for suspicion with a funnel-style debriefing and thanked for their participation.

\section{Pretest Value Importance}

In the first task, participants were given a list of 16 values from the Schwartz (1992) Value Survey, with four values serving each of the four higher order motivations: self-transcendence, selfenhancement, openness, and conservation (see Figure 1). The self-transcendence values were loyal, equality, helpful, and a world at peace; the openness to change values were an exciting life, a varied life, curious, and independent; the self-enhancement values were ambitious, social power, social recognition, and successful; and conservation values were detachment, moderate, politeness, and respect for tradition. Each value was presented beside a definition in parentheses (e.g., equality was defined as "equal opportunity for all"). Participants were asked to rank the values on the basis of their importance as guiding principles in their lives, such that the most important value was ranked as 1 and the least important value was ranked as 16 .

\section{Experimental Manipulation}

Value-prioritizing conditions. In each value-prioritizing condition, participants were shown (fictitious) average value rankings of Cardiff University students for each of the 16 values that were in the pretest measure of value importance. Participants were asked to read these rankings and their own rankings. Values serving the self-transcendence, openness to change, self-enhancement, or conservation motive were clearly prioritized in the average rankings for each experimental group. The values in the prioritized motivational domain were ranked from 1 to $4(M=2.5)$. The mean ranking for values from unrelated motivational domains was randomly either 10 or 11 , and the mean ranking for values serving the opposing domain was 10.5 .

Second, participants were asked to identify the four most highly ranked values in the reference group's ranking and to write the names of the values in a predetermined column. Participants completed the same task for their own value ranking, and they were asked to recognize the conceptual similarities and differences between their value rankings and the reference group's value rankings.

\footnotetext{
${ }^{2}$ Participants also completed a measure of satisfaction with pretest value rankings before the postmanipulation measure of value importance. This measure was included to complete the value self-confrontation paradigm, which is supposed to induce a broad sense of value dissatisfaction (Rokeach, 1973). Because this measure asked about satisfaction with the whole set of value rankings, rather than the subset of prioritized values (as studied in the $5 \times 4$ design), it was not appropriate for analysis within the $5 \times 4$ design.
} 
Third, participants were asked to read an explanation about the first four preferred values of the reference group and about the characteristics of people who rank those values as their most preferred values. The explanation was based on Schwartz's (1992) descriptions of the value types. For example, in the selftranscendence values condition, the explanation stated that

\begin{abstract}
the average of the students' value ranking shows that the most important values to students at Cardiff University are Loyalty, Equality, Helpfulness, and A World at Peace. Past research demonstrated that people who believe in these values always emphasize universal human requirements, and are very interested in understanding, appreciating, tolerating, and protecting the welfare of all close others and people in other settings. Therefore, based on the average of students' rankings, we can conclude that they have shown their concern for the welfare of all human beings, even those whose way of life differs from theirs.
\end{abstract}

To reinforce this aspect of the manipulation, we asked participants to write their own explanation of why students emphasized the four values. Most participants simply paraphrased the explanation that had been given to them.

Control condition. Participants in the control group were asked to complete an unrelated task. Specifically, they were asked to read a short passage about memory and to memorize 16 underlined terms (e.g., frontal lobe, verbal, short term, phonological). After doing this task for $10 \mathrm{~min}$, they were asked to read a new version of the same passage, wherein the 16 terms had been deleted. Participants were asked to insert the terms where they belonged in the passage.

\section{Posttest Value Importance}

In the last task, participants were given another set of 16 values from Schwartz's (1992) Value Survey. These values were different from the values used to represent each domain in the pretest measure. Four values were presented from each higher order domain. The four values that served self-transcendence motives were forgiving, honest, social justice, and broad-minded; the four values that served openness motives were creativity, daring, a stimulating life, and choosing own goals; the four values that served self-enhancement motives were authority, capable, influential, and wealth; and the four values that served conservation motives were devout, honoring of parents and elders, social order, and obedient. Participants were told that this set of values had not yet been studied in students and were asked to rank the importance of these values as guiding principles in their own lives, such that the most important value was ranked 1 and the least important value was ranked 16 (as in the pretest measure).

\section{Funnel Debriefing}

Finally, participants completed a funnel debriefing interview similar to the debriefing approach used in past research (Bargh \& Chartrand, 2000; Fitzsimons \& Bargh, 2003). This interview began with global questions about the session (e.g., "Were there any hypotheses that you thought we should, could, or would test?") to a more specific explanation of the experiment and pointed questions about their experience. Only 9 participants (out of 175) indicated any amount of suspicion that we were looking at value change during this debriefing. Most were puzzled with the notion of looking at value change, because they knew that we had used different values in the final measure of values.

\section{Results and Discussion}

\section{Effects of Condition and Value Type}

To examine the effects of the manipulation on changes in value rankings from pretest to posttest, we submitted the algebraic difference between the pretest and posttest rankings (pretest minus posttest) to a 5 (value prioritization: self-transcendence vs. openness to change vs. self-enhancement vs. conservation vs. control) $\times 4$ (value type: self-transcendence vs. openness to change vs. self-enhancement vs. conservation) mixed-model analysis of variance (ANOVA), with repeated measures on the second factor (see Rokeach, 1973, for details on this type of dependent measure). The results indicated a main effect of value type, $F(3,483)=4.83$, $p<.003$, such that conservation values $(M=0.22, S D=1.84)$ underwent greater positive change in importance than did selfenhancement values $(M=-0.33, S D=2.03), t(165)=-2.35$, $p<.02$, with the self-transcendence values $(M=-0.04, S D=$ $1.94)$ and openness to change values $(M=0.08, S D=1.85)$ in between. As expected, the main effect of condition was not significant, $F(4,161)=0.79$, ns, suggesting that there was no net increase or decrease in value importance between conditions.

More important, the results indicated a significant interaction between value prioritization and value type, $F(12,483)=69.09$, $p<.001$. This interaction is depicted in Figure 2. To provide an initial test of the circular model's applicability to this interaction, planned comparisons tested whether the values changed more positively in the condition that prioritized the motive expressed by the values than in the conditions that prioritized irrelevant motives or no motives (control). In the analysis of each value type, these planned comparisons were significant in the expected direction. For example, participants in the self-transcendence prioritized condition changed their self-transcendence values more positively than did participants in the openness to change, conservation, and control groups, $t(640)=10.00, p<.001$. We also conducted planned comparisons that tested changes in values that served opposing motives. These planned comparisons were also significant in the expected direction. For example, participants in the self-transcendence prioritized condition decreased the importance of their self-enhancement values more than did participants in the openness to change, conservation, and control groups, $t(640)=$ 7.43, $p<.001$.

In the conditions that provided self-confrontation feedback prioritizing the other types of values, the results were again perfectly consistent with the circular model. The self-enhancement condition led to greater importance for self-enhancement values than in the openness to change, conservation, and control conditions, $t(640)=$ 11.58, $p<.001$, while causing lower importance for selftranscendence values, $t(640)=10.19, p<.001$. Participants in the openness to change condition changed their openness values more positively than did participants in the self-transcendence, selfenhancement, and control groups, $t(640)=6.01, p<.001$, and they decreased the importance of their conservation values more than did participants in the self-transcendence, self-enhancement, and control groups, $t(640)=7.85, p<.001$. Finally, the conservation condition led to greater importance for conservation values than in the self- 


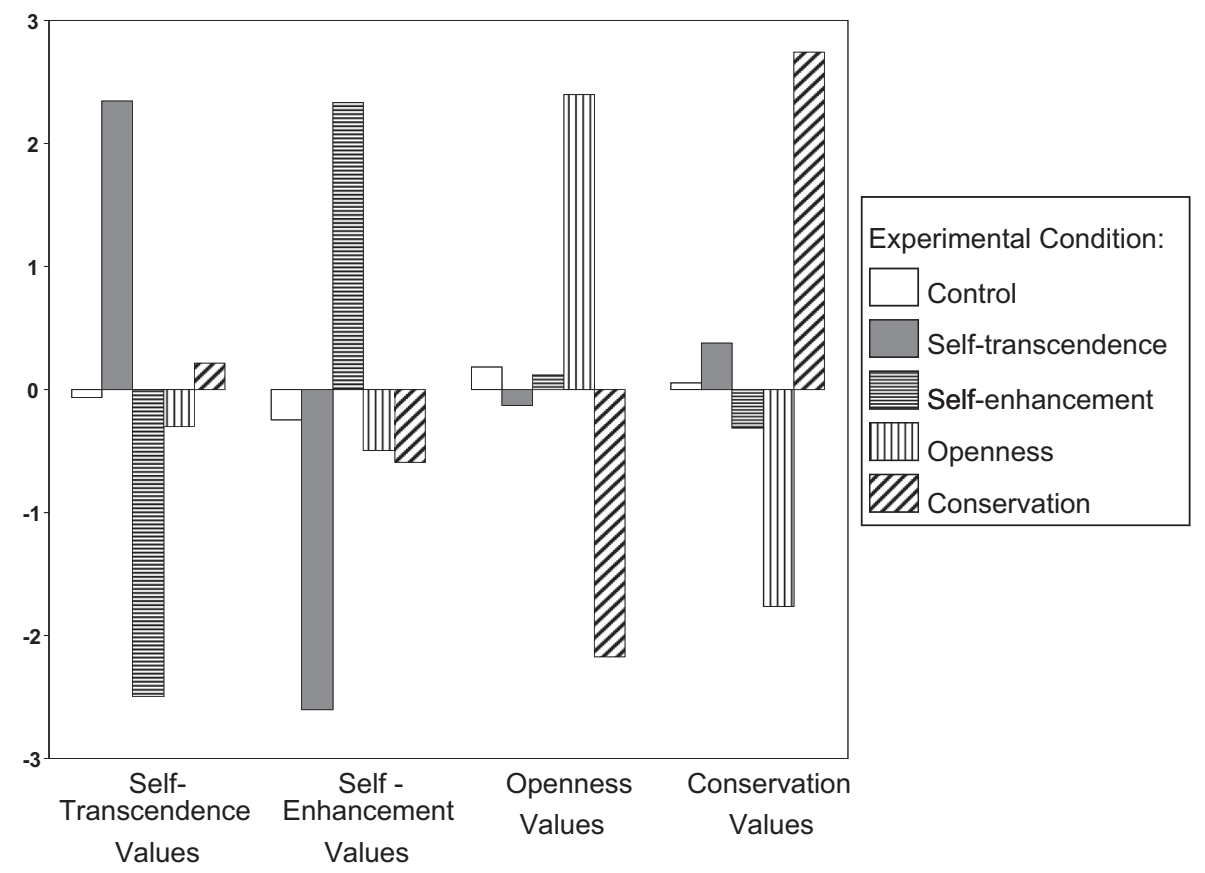

Figure 2. Experiment 1: Value change in each value prioritization condition for each type of value. Upward changes reflect increases in value importance.

transcendence, self-enhancement, and control conditions, $t(640)=$ $10.95, p<.001$, while causing lower importance for openness to change values, $t(640)=9.33, p<.001$.

To provide a more rigorous test of the circular model's application to this interaction, we calculated the 16 possible paired contrasts with the control condition in our $5 \times 4$ design. Eight of these contrasts focused on changes in the self-transcendence and self-enhancement prioritization conditions. For example, participants in the condition that prioritized self-transcendence values changed their self-transcendence values $(M=2.34, S D=0.21)$ significantly more positively than did participants in the control condition $(M=-0.06, S D=.21), t(640)=8.08, p<.001$, while changing their self-enhancement values $(M=-2.60, S D=0.22)$ more negatively than did participants in the control condition $(M=-0.25, S D=0.23), t(640)=9.60, p<.001$. As predicted, participants in the self-transcendence condition did not change their openness to change values $(M=-0.13, S D=0.20)$ or conservation values $(M=0.38, S D=0.20)$ significantly more or less than did participants in the control condition $(M \mathrm{~s}=0.18$ and 0.05 , respectively; $S D \mathrm{~s}=0.20), t \mathrm{~s}<1.08, n s$. In addition, participants in the self-enhancement condition changed their selfenhancement values $(M=2.33, S D=0.23)$ more positively than did participants in the control condition, $t(640)=8.69, p<.001$, while changing their self-transcendence values significantly more negatively $(M=-2.49, S D=0.21), t(640)=8.18, p<.001$. As expected, participants in the self-enhancement condition did not change their openness to change values $(M=0.12, S D=0.20)$ or conservation values $(M=-0.31, S D=0.20)$ significantly more than did participants in the control condition $(t \mathrm{~s}<1.22, n s)$.

The other eight contrasts focused on value changes in the openness to change and conservation prioritization conditions.
Participants in the openness to change condition increased the importance of their openness to change values $(M=2.40, S D=$ $0.20)$ relative to participants in the control condition, $t(640)=$ $7.47, p<.001$, while decreasing the importance of their conservation values $(M=-1.76, S D=0.20)$ relative to the control condition, $t(640)=7.74, p<.001$. As expected, participants in the openness to change condition did not change their selftranscendence values $(M=-0.30, S D=0.21)$ or selfenhancement values $(M=-0.49, S D=0.23)$ significantly more than did participants in the control condition $(t \mathrm{~s}<0.79$, $n s)$. In addition, participants in the conservation condition increased the importance of their conservation values $(M=2.74, S D=0.20)$ more than did participants in the control condition, $t(640)=9.03$, $p<.001$, while decreasing the importance of their openness to change values $(M=-2.17, S D=0.20), t(640)=7.39, p<.001$. As expected, participants in the conservation condition did not change their self-transcendence values $(M=0.21, S D=0.21)$ or self-enhancement values $(M=-0.59, S D=0.23)$ significantly more than did participants in the control condition $(t \mathrm{~s}<1.16, n s)$.

\section{Summary}

The results of Experiment 1 provided the first evidence for systemic change in values. Value self-confrontation support for targeted values caused changes in different posttest values that served similar and opposing motives. Values serving similar motives changed in the same direction as the promoted value, whereas values serving opposing motives changed in the opposite direction. As expected, values serving unrelated motives did not change. Thus, the pattern of value change fits the circular model's predictions about the compatibilities and conflicts between the motives that values express. 
Given this experiment's novel evidence that patterns of value change fit the circular model's assumptions about motivational interconnections, it is important to consider whether these motivational relations can yield systemic patterns in value-relevant behavior. Experiments 2 through 5 tested whether the activation of a set of values increases behavior that supports the values and decreases behavior that supports incongruent values. As noted in the introduction, these experiments did not examine effects on behaviors relevant to orthogonal values.

\section{Experiment 2}

Experiment 2 examined the effects of priming stimulation and tradition values. Schwartz's (1992) circular model indicates that stimulation values (e.g., a varied life, daring) drive a search for arousal that is sensationally or affectively pleasant, whereas tradition values (e.g., humble, accepting one's portion in life) respect and accept the imposition of external limits. These two sets of values belong to different and opposing categories of the higher order value types: stimulation values are in the higher order category of openness to change values, whereas tradition values reside in the higher order category of conservation values. The latent motivational conflict between these values should cause the activation of stimulation values to decrease behavior that affirms tradition values, whereas priming tradition values should of course increase behavior that affirms these values.

To test this hypothesis, we examined the effect of priming these types of values on the better-than-average effect (Alicke, Klotz, Breitenbecher, Yurak, \& Vredenburg, 1995), which is the tendency to express more superior evaluations of the self compared with others. This effect is relevant to tradition values because self-enhancement bias in general is fed by difficulties in recognizing one's own place (Anderson, Srivastava, Beer, Spataro, \& Chatman, 2006) and limitations (Kruger \& Dunning, 1999). Tradition values emphasize accepting such constraints in a manner that diminishes the personal self. This emphasis is best characterized by the tradition values of humble, accepting my portion in life, and moderate (see Table 1). People primed with these values should experience a stronger motivation to be modest, causing a lower better-than-average effect.

More novel, the circular model predicts that the motivational orientation served by tradition values competes with the motivational orientation served by stimulation values. Core examples of the latter values are daring, a varied life, and an exciting life. These values promote excitement, novelty, and challenge. By emphasizing personal pursuits and satisfaction, they subtract from tradition values' emphasis on the connections between self and others (e.g., Streib, 1999). Indeed, stimulation values are virtually adjacent to self-enhancement values in the circular model (because Schwartz, 1992, indicates that the intervening, hedonism values can be considered to be either self-enhancement or openness to change values), and selfenhancement values directly involve this self-inflation. It is therefore plausible that stimulation values involve a motivational orientation that is antithetical to the self-effacing mind-set that promotes modesty in the better-than-average effect. People primed with these values should experience less motivation to be modest, causing a higher better-than-average effect.

However, the better-than-average effect may occur through two different mechanisms: self-enhancement and denial (Paulhus,
2002). Self-enhancement is about promoting positive attributes, and denial is about disavowing negative attributes (Paulhus \& Reid, 1991). Both mechanisms serve to maintain relatively high levels of self-esteem (Alicke et al., 1995; Taylor \& Lobel, 1989), and it is conceivable that the tradition values lead to lower selfenhancement or less denial or both. To examine these possibilities, Experiment 2 included both positive and negative traits in the measurement of the better-than-average effect.

\section{Method}

\section{Participants}

In this experiment, 116 Cardiff University undergraduate psychology students ( 84 female, 32 male) participated for course credit. Participants were tested in a group setting with a maximum group size of 6 . They were informed that there were several tasks to complete. The experimenter presented the experimental manipulation, followed by two measures that were irrelevant to the better-than-average effect and then the task measuring the betterthan-average effect. Participants also completed a funnel debriefing interview similar to the debriefing used in Experiment 1.

\section{Experimental Manipulation}

As in prior research (Chartrand \& Bargh, 1996; Walther, 2001), the priming task involved unscrambling 15 sentences containing values or control items. The sentences included stimulation values (e.g., stimulation, an exciting life, a varied life), tradition values (e.g., moderate, tradition, humble), or the names of furniture items (e.g., table, drawer, armchair).

\section{Tradition Behavior}

To examine the better-than-average effect with the same traits as used in research by Alicke et al. (1995), we had participants rate the extent to which they possessed 20 positive traits (e.g., intelligent, respectful) and 20 negative traits (e.g., deceptive, disobedient) when compared with an average student at the same university. Participants responded to each trait on a scale from 1 (much less than average university student) to 9 (much more than average university student). The scores of the negative traits were reverse-scored so that a higher value reflected a higher positive bias. There were two positive and two negative traits on each page, and the 10 pages were given to the participants in a randomized order.

\section{Results and Discussion}

We conducted a 3 (stimulation vs. tradition vs. control) $\times 2$ (trait valence) $\times 2$ (gender) mixed-model ANOVA on participants' ratings of themselves relative to the average person. ${ }^{3}$ The results indicated a main effect of trait valence, $F(1,103)=4.94, p<.03$, such that participants rated themselves as being more superior to the average person on negative traits $(M=115.86, S D=1.63)$ than on positive traits $(M=112.45, S D=1.57)$.

\footnotetext{
${ }^{3}$ Our sample in this experiment was large enough to control for a potential effect of gender on better-than-average scores, which was important because of gender differences in self-effacement (e.g., Kitayama, Markus, Matsumoto, \& Norasakkunkit, 1997).
} 
This effect was qualified by a significant interaction between the value-priming manipulation and trait valence, $F(2,103)=3.17$, $p<.05$. To interpret this interaction, we examined the effects of the value primes on the magnitude of the better-than-average effects for the positive traits and for the negative traits (see Figure 3 ). There were no significant differences in the magnitude of the better-thanaverage effects for the positive traits $(M \mathrm{~s}=111.10,112.45$, and 113.79 , in the tradition, control, and stimulation conditions, respectively; $p s>.20)$. In contrast, the better-than-average effect for the negative traits was significantly weaker after the tradition values were primed $(M=109.56, S D=2.83)$ than after the control primes $(M=116.62, S D=2.98), t(103)=2.97, p<.01$, and significantly stronger after the stimulation values were primed $(M=121.39, S D=2.67)$ than in the control condition, $t(103)=$ $2.09, p<.05$.

The results supported the hypothesis that priming tradition values causes more modesty in self-evaluations. This modesty was significantly lowered when values that express an opposing motive (stimulation) were activated. Nevertheless, these effects occurred only when we examined personal ratings on negative traits but not the ratings on positive traits. The negative trait ratings tap the denial component of the better-than-average effect, whereas the positive trait ratings tap the self-enhancement component of the effect (Paulhus, 2002). Our results indicate that value primes affect the extent to which the people deny negative attributes, whereas their tendency to self-enhance is relatively robust and resistant to interference. This observation converges with other evidence for relatively robust self-enhancement effects (Alicke, 1985; Alicke et al., 1995): Self-enhancement may be too basic and powerful to be influenced by a recent, brief priming event, whereas the denial effect may be more multiply determined and therefore amenable to influence. Future research is needed to discover why the mechanism underpinning self-enhancement is more robust in the face of brief value primes. This issue aside, the results clearly supported our hypotheses that priming with tradition and stimulation values causes opposing effects on modesty in self-evaluations, congruent with the circular models.

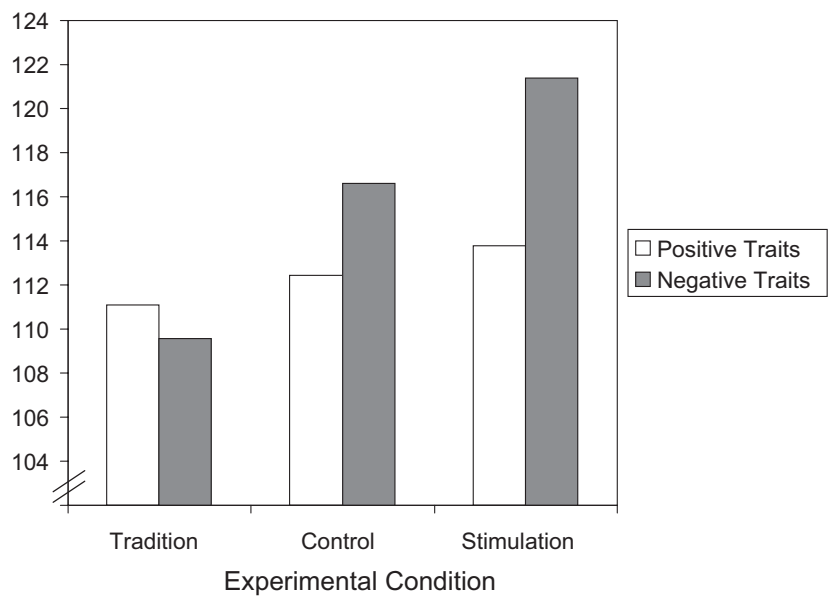

Figure 3. Experiment 2: Tradition behavior (modesty in the better-thanaverage effect) for positive and negative traits in each value-priming condition.

\section{Experiment 3}

Experiment 3 examined the effects of priming two different sets of values: security values (e.g., social order, clean) and selfdirection values (e.g., creativity, curious). According to Schwartz's (1992) model of values, security values help to avoid the threat of uncertainty and to conserve the existing order, whereas self-direction values promote exploration and independence. Like the tradition and stimulation values examined in Experiment 2, security and self-direction values lie in opposing positions on the dimension from conservation values to openness to change values (see Figure 1). Thus, participants should demonstrate more behavior that affirms the primed values than do participants who are primed with the opposing value, with the control group in between.

To examine this hypothesis, Experiment 3 tested whether the activation of security values increases behavior that promotes security, whereas the activation of self-direction values decreases this behavior. Experiment 3 tested this prediction with a measure of security-promoting behavior: cleanliness. As shown at the bottom of Table 1, cleanliness is one of the security-promoting values in Schwartz's (1992) circular model. Cleanliness is a securitypromoting value because it contributes to safety, harmony with others, and adherence to social norms. Thus, any task that primes security-oriented values should also increase concern about cleanliness.

More important, the circular model also predicts that this security orientation is opposed by self-direction values, which emphasize exploration and independence. Self-direction values entail a creative, exploratory mind-set that is less concerned about prevailing social standards. Creativity itself entails following novel directions without rigid application of fixed rules and norms (Kuhnen, Hannover, \& Schubert, 2001). Thus, although this pursuit can entail cleanliness (as in five-star restaurants and some art studios), it involves a mind-set that can often be inimical to this behavior. Indeed, people rate cleanliness and other security values as stronger reflections of what they "ought to do" than of what they "ideally would do," whereas the opposite occurs for creativity and other self-direction values (Rees \& Maio, 2007). This competition should cause self-direction value primes to reduce behavior that affirms security values, such as cleanliness. Overall, then, we expected security value primes to increase cleanliness, whereas self-direction value primes should reduce cleanliness.

\section{Method}

\section{Participants and Procedure}

In this experiment, 58 Cardiff University undergraduate psychology students (52 female, 6 male) participated for $£ 3$. Participants were tested individually and were informed that there were several tasks to complete. They completed an experimental manipulation similar to the manipulation used in Experiment 2, except that participants rearranged scrambled sentences including self-direction values (e.g., choosing own goals, curiosity, freedom), security values (e.g., national security, social order, clean), or the names of clothing items (e.g., skirt, shoes, boots).

Participants were then given a slightly leaky pen to complete the remaining tasks (e.g., consumer preference ratings, problem solving). One of the tasks required that participants join broken lines in 
a picture of dolphin, before coloring it with old, used crayons that were messy and slightly sticky. Cleaning wipes and tissues were provided next to crayons on the desk at which the participants were seated for all of their tasks. We recorded the interval at which the participants requested another pen or used the cleaning wipes as the measure of cleanliness behavior, such that higher scores were given for attempts to be clean in an earlier task. That is, participants received a score of 4 if they first used a new pen or the cleaning wipes while doing the initial consumer preference task, a score of 3 if the new pen or wipes were first used while doing the drawing and coloring task, a score of 2 if participants did not replace the pen and only used wipes at the end of the experiment, and a score of 1 if the clean pen or wipes were not used at all. Participants were probed for suspicion and debriefed with the funnel debriefing procedure described in Experiment 1.

\section{Results and Discussion}

To examine the effects of the manipulation of priming condition (self-direction vs. security vs. control) on cleanliness behavior, we conducted a one-way ANOVA. The results revealed a main effect of condition, $F(2,55)=4.35, p=.02$, with participants in the security condition $(M=3.21, S D=0.92)$ requesting another pen or using the cleaning wipes earlier than did participants in the self-direction condition $(M=2.30, S D=0.87), t(55)=-2.93$, $p=.01$ (see Figure 4). A planned pairwise comparison revealed that participants in the security condition tended to request another pen or use the wipes earlier than did participants in the control condition $(M=2.84, S D=1.12)$, but this contrast did not reach conventional levels of significance, $t(55)=1.17, p=.24$. In contrast, participants primed with self-direction values delayed cleanliness to a marginally greater extent than did participants in the control prime condition, $t(55)=1.74, p=.08$. The direction of these contrasts was again consistent with the predictions derived from the circular model.

The results from Experiment 3 provided further evidence that priming one value not only promotes behavior that fulfills the motive expressed by the value, but it also decreases behavior consistent with a motive expressed by opposing values. In this case, participants' cleanliness decreased after being primed with

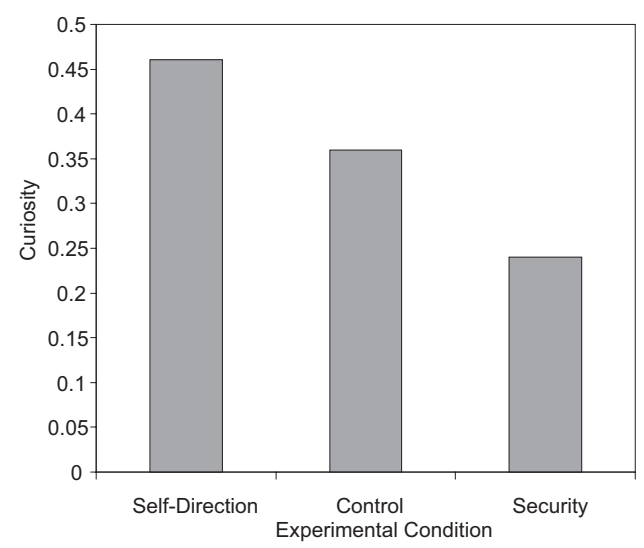

Figure 4. Experiment 3: Security behavior (cleanliness) in each valuepriming condition. self-direction values, relative to the effect of being primed with security values. Although the main effect was significant and consistent with our predictions, the specific comparisons with the control condition did not reach conventional levels of significance. Nonetheless, the tendency for the self-direction prime to decrease cleanliness was reliable with a one-tailed test $(p<.04)$, which is justified by our a priori hypotheses. This particular comparison is more central to our predictions (than is the comparison between the security prime and control) because of its relevance to the latent motivation conflicts that we are attempting to illustrate. Nonetheless, it was useful to conduct another experiment testing our hypotheses regarding the security to self-direction dimension.

\section{Experiment 4}

By concentrating on a behavior that affirmed security values, Experiment 3 examined only one half of the potential systemic effect of priming self-direction and security values. The other half of the systemic effect is that behavior promoting self-direction values should increase following the activation of these values but decrease after the activation of security values. Experiment 4 tested these predictions.

Experiment 4's behavioral measure was based on the value of curiosity, which is one of the self-direction values identified in Schwartz's (1992) circular model. We examined curiosity by giving participants an opportunity to request information about the answers to diverse quiz questions. Curiosity about the answers should be enhanced after the activation of curiosity and other self-direction values, which explicitly promote an exploratory, independent mind-set. The circular model predicts that this mindset is negated by the uncertainty-avoiding mind-set that underpins security values, which are more concerned with stability and avoidance of threat. Indeed, this view fits several major theoretical perspectives proposing that social order, commitment to groups, and positive group feeling serve partly to reduce psychological uncertainty (Lawler, Thye, \& Yoon, 2000). This view also fits the frequent use of authoritarian belief scales (which tap prosecurity motives; see Oesterreich, 2005) to help assess an aversion to uncertainty (Sorrentino et al., 2008). Thus, a confluence of perspectives supports the hypothesis that the activation of security values may reduce the strength of curiosity-driven behavior.

\section{Method}

\section{Participants and Procedure}

In this experiment, 60 Cardiff University undergraduate psychology students (49 female, 11 male) participated for course credit. Participants were tested either individually or in a group with a maximum number of 5 . They were informed that there were several tasks to complete. These tasks included the experimental manipulation and a measure of self-direction behavior. Then, participants were probed for suspicion and debriefed with the funnel debriefing procedure described in Experiment 1.

\section{Experimental Manipulations}

We attempted to conceptually replicate the effects obtained in Experiments 2 and 3 by using a different priming task. Specifically, we devised a novel sorting task to activate values. 
Value-priming conditions. In each priming condition, participants were asked to complete a sequence of tasks. First, they were given a table including values (and near-synonyms of the values) from the primed value domain (e.g., self-direction) and the names of some items of clothing (e.g., boots). The values were printed adjacent to positive adjectives (e.g., happy, excellent, ideal, perfect, pretty), and the clothing items were printed adjacent to neutral adverbs (e.g., normal, usual, typical, ordinary, common). ${ }^{4}$ The values and items of clothing were located in a column labeled Main Terms, and the positive and neutral adjectives were located in an adjacent column labeled Adjectives.

Participants were asked to memorize main terms and their adjectives and then, after $3 \mathrm{~min}$, to recall and write down the main terms and their adjacent adjectives. The experimenter asked participants whether they noticed any meaningful categories of main terms and their adjectives while trying to memorize them. The experimenter explained that the main terms could be divided into clothing and social concept categories and that the adjectives could be divided into positive and neutral categories. Participants were then given another set of clothing items, values, and adjectives based on their categories to memorize, with the explanation that the experimenter wished to see whether they could memorize more terms after the categories were made known to them.

After 3 min, participants were again asked to recall and write down the main terms and their adjectives. Participants in the self-direction condition always received self-direction values (e.g., choosing own goals, curiosity, freedom) across the two memorization tasks, whereas participants in the security condition always received security values across the tasks (e.g., national security, social order, clean). Participants in the control group went through almost the same process as for the priming conditions, except that for their categories they received names of colors instead of values.

\section{Behavioral Measures}

We measured the promotion of self-direction by examining postmanipulation curiosity: the openness and eagerness to acquire new information. Participants responded to 48 quiz questions about various topics, including history, movies, sports, music, science, geography, celebrities, politics, literature, myths, and legends. After each response, participants indicated whether they knew the answer and whether they would like to receive further information about the answer. To calculate curiosity from these responses, we calculated the ratio of the number of questions each participant wanted to know more about to the number of questions for which they did not know the answer. Higher ratios thus indicated higher levels of curiosity (independent of actual knowledge).

\section{Results and Discussion}

To examine the effects of the priming manipulation (selfdirection vs. security vs. control) on value-consistent behaviors, we conducted a one-way ANOVA. The results revealed a main effect of condition on curiosity behavior, $F(2,57)=4.92, p=.02$, with the self-direction condition $(M=0.46, S D=0.28)$ showing higher curiosity than did the security condition $(M=0.24, S D=$ $0.18), t(57)=3.13, p<.01$ (see Figure 5). Planned pairwise contrasts with the control condition revealed that participants who

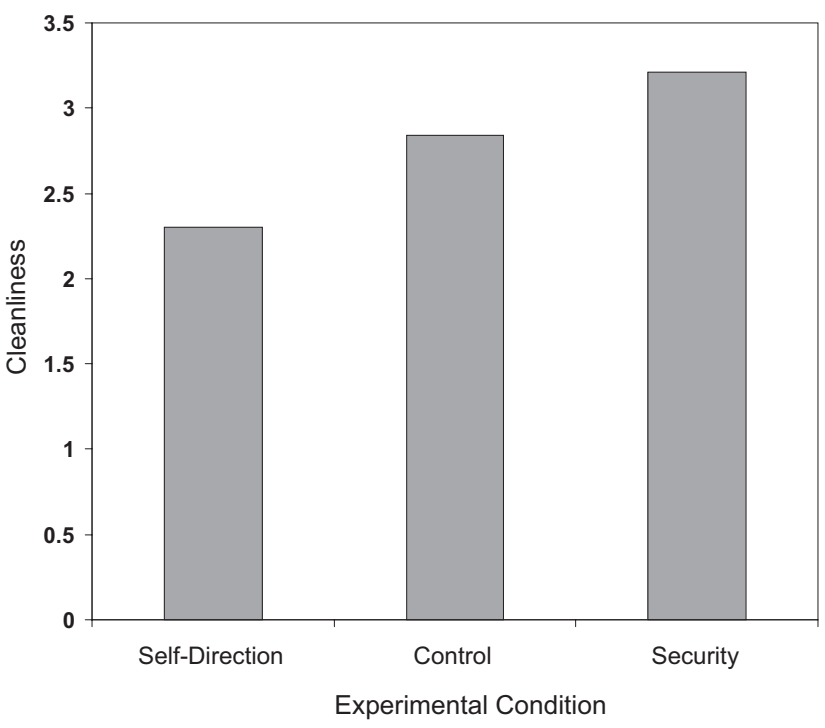

Figure 5. Experiment 4: Self-direction behavior (curiosity) in each valuepriming condition.

were primed with self-direction values tended to exhibit greater curiosity than did participants in the control group $(M=0.36$, $S D=0.21), t(57)=1.35, p=.18$, but this contrast did not reach conventional levels of significance. In contrast, participants primed with security values exhibited marginally less curiosity than did participants in the control group, $t(57)=1.78, p=.08$. The direction of these planned comparisons was consistent with the predictions derived from the circular model.

The data from Experiment 4 provided novel evidence that priming a set of values both promotes behavior that is consistent with the values and decreases behavior consistent with opposing values. In this case, participants' curiosity decreased after being primed with security values, relative to the effect of being primed with self-direction values. As in Experiment 3, the main effect was significant and consistent with our predictions, but the specific comparisons with the control condition did not reach conventional levels of significance. Nonetheless, the tendency for the security prime to decrease curiosity was reliable with a one-tailed test ( $p<$ $.04)$, which is justified by our a priori hypotheses. This particular comparison is more central to our predictions (than is the comparison between the self-direction prime and control) because of its relevance to the latent motivation conflicts that we are attempting to illustrate.

Overall, the effects of the value primes on behavior that supports opposing values were consistent across both of the experiments examining self-direction and security values (Experiments 3 and 4). In addition, the nonsignificant effects of value-consistent priming (i.e., security increasing cleanliness and self-direction increasing curiosity) should not be dismissed: These effect sizes were in the predicted direction, small to moderate in magnitude $(r=.16$ in

\footnotetext{
${ }^{4}$ This pairing with positive adjectives was used because the chosen values are all associated with high importance and positive feelings (Maio \& Olson, 1998; Schwartz, 1992). Thus, the pairing reflects the natural affective associations that participants already possess for the values.
} 
Experiment 3, $r=.18$ in Experiment 4), and, to foreshadow, value-consistent priming effects were reliable in Experiment 5 (as in Experiment 2). Some weaker contrasts are to be expected across any large set of experiments examining small-to-moderate effect sizes (Cohen, 1988).

\section{Experiment 5}

Although the data from Experiments 2 through 4 supported our predictions about the effects of value priming, they focused on only one of the dimensions in the circular model of values. Specifically, these experiments focused on the dimension from openness to change values (stimulation values in Experiment 2; self-direction values in Experiments 3 and 4) to conservation values (tradition values in Experiment 2; security values in Experiments 3 and 4). To more fully test the circular model's assumptions about motivational interconnections, we should examine the effects of priming values along the other value dimension, from self-enhancement values to self-transcendence values (see Figure 1).

Another limitation of the prior experiments is that they each assessed only one behavior, which was meant to express one type of value. Although we argued in the introduction that a consistent pattern of results across experiments should be compelling, it would nonetheless be more compelling to also show that the same manipulation exerts a significantly different (opposing) impact on a second behavior that expresses opposing values. This focus would be similar to the design of Experiment 1, which found that a manipulation of value change significantly interacted with the type of value change being measured. In this case, the focus would be on testing whether a manipulation of value priming interacts with the type of behavior being measured.

To address these issues, Experiment 5 came back full-circle to two motivational domains that have been used to demonstrate classic priming effects described in the introduction (Bargh et al., 2001; Macrae \& Johnston, 1998). Specifically, we examined the effect of priming achievement values (e.g., successful, capable) and benevolence values (e.g., helpful, loyal) on behaviors that promoted achievement and benevolence. These sets of values reside within the self-enhancement (achievement) and selftranscendence (benevolence) domains of the circular model. In Schwartz's (1992) model of value structure, the achievement and benevolence value types are opposing: Benevolence values preserve and enhance the welfare of others, whereas achievement values emphasize personal success. Although these motives can be compatible (e.g., when winning money for self and others in a game), they tend to be implicitly regarded in opposition (Grouzet et al., 2005; Pakizeh et al., 2007; Vohs et al., 2006). Consequently, priming one value type may inhibit behavior that affirms the other value type.

For example, the achievement behavior in this experiment involved completing word puzzles, as in research conducted by Bargh et al. (2001). These researchers found that success at this task was enhanced by achievement priming. Although this task did not directly compete with benevolent behavior (i.e., assisting others) in our laboratory context, the circular model predicts that priming benevolence would decrease success at the task because the benevolence prime elicits a competing motivational orientation. Benevolence values correspond with a focus on the welfare of others, and this outward focus is opposite in direction from the inward, self-rewarding focus that energizes achievement values. Thus, priming benevolence values may undermine the motivational orientation that drives success at the word puzzle task.

Similarly, the benevolence behavior in this experiment involved freely volunteering to help the researcher complete an additional experiment, as in research conducted by Maio et al. (2001). At the university where this research was conducted, participants already complete a high amount of experimental participation per year for course credit ( $20 \mathrm{hr}$ per year for 2 years), so there is little pedagogical benefit from additional participation without course credit. Instead, there is evidence that volunteering for research in this setting is motivated by the value of helpfulness (Maio et al., 2001). Thus, a manipulation that activates this value and other benevolent values should increase participants' commitment to volunteering. At the same time, a manipulation activating achievement values should elicit a self-focused orientation that negates the selftranscending orientation that underlies the willingness to volunteer. According to the circular model, the achievement orientation is distinctly self-focused and less amenable to a concern for aiding others.

\section{Method}

\section{Participants and Procedure}

In this experiment, 112 Cardiff University undergraduate psychology students ( 67 female, 45 male) participated for $£ 4$. The data from 5 participants were removed from the analysis because of suspicion.

Participants were tested individually and were told that the session included several tasks. First, they completed the experimental manipulation, which employed the sorting task used in Experiment 4. Next, participants completed a measure of achievement behavior and then a measure of benevolence behavior. ${ }^{5}$ Finally, participants were probed for suspicion and given a funnel debriefing interview similar to that described in Experiment 1.

\section{Experimental Manipulation}

The priming manipulation was the same as in Experiment 4, except that the value-priming conditions asked participants to sort achievement values (e.g., ambitious, capable, successful) or benevolence values (e.g., forgiving, helpful, honest) from adjectives and items of furniture (e.g., chair, drawer, table). In the control condition, participants sorted the names of food items (e.g., ham sandwich, veggie pizza) from the adjectives and items of furniture.

\section{Achievement Behavior}

Similar to past research (Bargh et al., 2001), the measure of achievement gave participants $5 \mathrm{~min}$ to complete a word search task within a table of letters that included the names of British

\footnotetext{
5 These measures were separated by a measure of responses to a hypothetical scenario involving achievement and a scenario involving benevolence. Responses to these scenarios replicated the pattern obtained for the behavioral measures but are not described because of our principal focus on overt behavior.
} 
cities, items of furniture, and colors (total $N=24$ ). The total number of detected words was recorded as the measure of achievement.

\section{Benevolence Behavior}

For the last dependent measure, the researcher asked participants whether they would be willing to take part voluntarily (without payment) in some future research. He explained that he needed to complete some more experiments but had no more money in his departmental account. If they agreed to take part in the research, they could choose an experiment lasting one of six amounts of time: $10,20,40,60,90$, or $120 \mathrm{~min}$.

\section{Results and Discussion}

To examine the effects of the manipulation on value-consistent behaviors, we conducted a 3 (value prime condition: achievement vs. benevolence vs. control) $\times 2$ (behavior: achievement vs. benevolent) mixed-model ANOVA, with repeated measures on the second factor. Prior to conducting this analysis, we standardized the achievement and benevolence behavior scores in order to make their scale range compatible for inclusion in the same analysis (enabling us to test for the Prime $\times$ Behavior interaction). The results revealed a marginal main effect of condition, $F(2,104)=$ 2.47, $p<.09$, such that the benevolence condition tended to elicit more achievement and benevolence behavior combined $(M=$ $0.16, S D=0.66)$ than did the control condition $(M=-0.15, S D=$ $0.53), t(69)=2.19, p<.03$, with the achievement condition in between $(M=-0.01, S D=0.57)$. The main effect of behavior was nonsignificant, $F(1,104)=0.00, n s$.

More important, the results indicated a significant Condition $\times$ Behavior interaction, $F(2,104)=57.60, p<.001$. Figure 6 depicts this interaction in terms of the raw, nontransformed variables (i.e., the number of words detected and the amount of time volunteered). Examination of the interaction supported our predictions: Participants exhibited more behavior supporting the motive expressed by the primed values than did participants in the control condition and in the condition that primed values expressing the opposing motives. Specifically, participants in the achievement condition exhibited more achievement behavior $(M=0.71, S D=$ 0.98) than did participants in the control condition $(M=-0.17$, $S D=0.84), t(69)=4.54, p<.001$, and the benevolence condition $(M=-0.54, S D=0.74), t(70)=6.46, p<.001$, whereas participants in the benevolence condition exhibited more benevolence behavior $(M=0.85, S D=0.91)$ than did participants in the control condition $(M=-0.13, S D=0.68), t(69)=5.05, p<.001$, and the achievement condition $(M=-0.73, S D=0.66), t(70)=$ $8.19, p<.001$. Of particular interest, participants exhibited less behavior supporting the motive opposed to the primed values than did participants in the control conditions. For example, participants in the achievement condition exhibited significantly less benevolence behavior than did participants in the control condition, $t(69)=3.06, p<.001$, and participants in the benevolence condition exhibited marginally less achievement behavior than did participants in the control condition, $t(69)=1.88, p<.07$.

Overall, the results indicated that the effects of value primes depend on whether the behavior being assessed expresses the value being primed or an opposing value. As expected, the significant
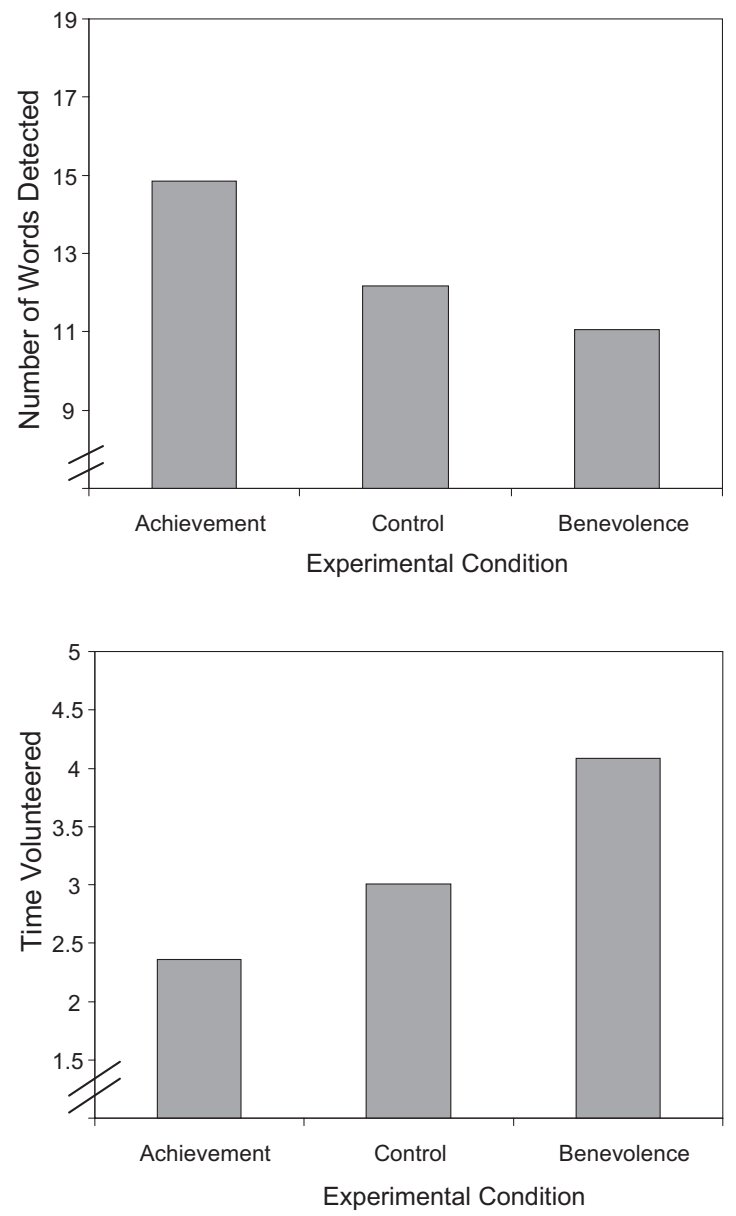

Figure 6. Experiment 5: Achievement behavior (number of words detected) and benevolent behavior (time volunteered) in each value-priming condition, after converting back from the $z$ scores used in the analysis Participants volunteered the following intervals of time: $1=10 \mathrm{~min}, 2=$ $20 \mathrm{~min}, 3=40 \mathrm{~min}, 4=60 \mathrm{~min}, 5=90 \mathrm{~min}$, and $6=120 \mathrm{~min}$.

interaction between value prime and type of behavior revealed that the effects of the value primes on each type of behavior went in opposing directions. Activating achievement and benevolence values increased the likelihood of behavior affirming the motive expressed by the values while decreasing the likelihood of behavior affirming the motive expressed by the opposing values.

\section{General Discussion}

The results across five experiments indicated that changing or priming any particular set of values has predictable implications via their motivational interconnections with other values. Experiment 1 revealed that the induction of changes in a set of values caused increases in the importance of different values promoting the same latent motivation while decreasing the importance of different values that promote an opposing motive. Moreover, changes in a set of values did not affect different values promoting orthogonal motives. This systemic pattern provides an important extension to the findings obtained by Rokeach (1973), who focused on changes in only the targeted values. Similarly, Experi- 
ments 2, 3, 4, and 5 revealed that priming a set of values increases behavior that affirms the values while decreasing behavior that affirms a set of opposing values. The consistent pattern across the measures of actual behavior in the priming experiments provides additional support for the notion that values map onto latent motivational conflicts and compatibilities, as predicted by the circular model of values (Schwartz, 1992). Together, the experiments provide an important extension of prior studies that examined the effects of value priming on only value-congruent behavior (e.g., Bargh et al., 2001; Macrae \& Johnston, 1998) by revealing a wider potential impact of values than has been revealed previously.

The results make clear that, when changing or priming values with the purpose of altering value-relevant attitudes or behavior, researchers should consider indirect effects of prioritized values on nontargeted attitudes and behaviors. The importance of such indirect effects has also been suggested in research on attitude change (Fishbein \& Ajzen, 1981), but this suggestion has not been accompanied by a model that can predict the nature of these indirect effects or methods of detecting indirect effects. The present research reveals a basis for predicting indirect effects. That is, when a procedure entails value change or mere value activation, indirect effects can be predicted by considering the motivational interconnections between values.

This evidence makes it compelling to also test whether indirect effects of other constructs that are linked to motives, including personal goals and aspirations, can be modeled in a similar way. For instance, when a procedure entails change or activation of personal goals, it should be useful to know the motivational interconnections between them. Grouzet et al.'s (2005) model of conflicts and compatibilities between personal goals provides the most appropriate basis for examining the effects of latent motivational conflicts from personal goals. In theory, personal goal change and priming should increase the importance and pursuit of adjacent goals, diminish the importance and pursuit of opposing goals, and have no effect on orthogonal goals. These results would provide important support for the model's claims about the motivational interconnections between personal goals. If these results occur, an intriguing and useful follow-up would examine the extent to which the motivational interconnections between values and between personal goals yield distinct contributions to behavior. These aims were beyond the scope of the present investigation, but our evidence provides a provocative basis for expecting that these topics are worth investigating.

\section{Limitations}

Although the present research yielded consistent evidence for systemic effects of values, several limitations of the designs should be noted. For instance, Experiment 1 detected value change over a short period of time after the value self-confrontation procedure. Although the results provided a powerful indication of latent motivational conflicts between different values, Rokeach's (1975) value self-confrontation procedure has previously elicited change that persisted over 6 months. It would be interesting to discover the duration of the present effects on different, nontargeted values. In addition, there is a need for research examining procedures that are less heavy-handed and more subtle than the value selfconfrontation procedure.
Another limitation is that the procedure in Experiment 1 assessed changes in value rankings rather than changes in value ratings. The iterative nature of value rankings means that upward changes in one set of rankings forces downward changes in other value rankings (Maio, Roese, Seligman, \& Katz, 1996). This iterative measurement cannot fully explain the results of Experiment 1 , because there was no significant downward value change in any of the values that were orthogonal to the values prioritized in the feedback: The change always occurred in the opposing value domain. Nonetheless, convergence across different measurement methods would provide a powerful extension of our findings.

Other limitations are varied. For instance, our participant samples were always United Kingdom undergraduates, thus limiting the generalizability of the findings. In addition, we did not include conditions that primed orthogonal values in the studies of value priming (unlike Experiment 1's examination of value change). Results in these conditions should have been more or less the same as those found in the control conditions, but it would be ideal to test this prediction.

Also, in any studies of priming effects, the dependent measure of behavior may reflect constructs other than those that were primed (e.g., different goals, scripts). In our experiments, the dependent measures of behavior could be plausibly linked to other values beyond those that were primed. The lack of value-behavior specificity makes it important that a consistent pattern was revealed across experiments, but it is nonetheless important for future research to investigate methods for more closely tuning the measures of behavior to the values that are primed.

\section{Mechanisms}

Some interesting questions about the mechanisms that explain the effects of value priming remain. Our research was guided by the circular model's prediction that values express specific motivational orientations, which conflict with other specific motivational orientations. Extant evidence indicates that activation of a motive affects the way in which we construe situations, such that we are quicker to detect ways in which current actions, objects, and people can be used to fulfill our motives (e.g., Ferguson \& Bargh, 2004; Fitzsimons \& Shah, 2008). Consistent with this evidence, the desire to achieve should make us construe a simple word puzzle as an opportunity to gain personal success rather than see it as merely a boring task or a chance to have fun. Thus, if the activation of achievement values increases the desire for personal success and reduces the concomitant desire to help others (as in Experiment 5), then people who have been primed with achievement should be both more likely to see a puzzle as a chance to succeed and less likely to construe a request to volunteer as a chance to be helpful.

Although our behavioral measures consistently fit our assumed mechanism, they cannot rule out all other possibilities. For instance, Kruglanski et al. (2002) articulated how goals can be arranged hierarchically, such that some goals are subsumed by other goals. It is possible that the effects predicted by the circular model of relations occur partly because values that serve opposing goals are less likely to promote the same higher order goal than are values that serve the same goal or an adjacent goal. For instance, it may generally be more difficult to view the values wealth and helpful as promoting the same goal than it is to view wealth and 
social power as promoting the same goal (e.g., achievement). This mechanistic prediction is important because it is possible that the ease of mapping onto higher order goals changes in different contexts. To continue our example, prior recitation of a list of philanthropists might make it easier to regard wealth and helpfulness as expressions of a compatible higher order goal (e.g., benevolence) than would prior recitation of a list of corporate leaders. Indeed, this speculation is consistent with other evidence indicating that the effects of value activation on subsequent action depend on the content of prior value instantiations (Maio, Hahn, Frost, \& Cheung, in press; Maio et al., 2001). In the long run, research should evaluate multiple perspectives on the mechanisms that mediate the effects of value priming.

\section{Applied Implications}

The present evidence offers a unique perspective on diverse applied issues that are connected to values. For instance, many theories suggest that conflict between values causes prejudice and discrimination toward diverse groups, including people with disabilities (Soder, 1990), homosexuals (Herek, 2000), obese people (Crandall et al., 2001), and Blacks (Katz \& Hass, 1988). The attribution-value model of prejudice (Crandall et al., 2001; Crandall \& Martinez, 1996), the aversive racism model (Gaertner \& Dovidio, 1986, 2005), and the ambivalence model of prejudice (Katz \& Hass, 1988) all stress conflict between benevolenceoriented and achievement-oriented cultural values as sources of prejudice toward people or groups. The results of our experiments complement these insights by revealing that behavior can be affected not only by increasing the activation of values promoting that behavior but also by decreasing the activation of opposing values. Given these results, discrimination may be reduced either by increasing the perceived importance of values promoting benevolence or by decreasing the perceived importance of values promoting achievement, because changes in either set of values have reciprocal effects on the opposing values. Future research should test whether such reciprocal effects do indeed affect prejudice and discrimination.

Other attitudes and behaviors may be made difficult because of latent conflict between relevant values. People wish to protect the environment, but actions often fail to match this value; people also wish to be healthy but find themselves failing to eat right and exercise (see Maio et al., 2007, for a review). In each case, people may underestimate the effect of situational constraints on them, but they may also underestimate competing motives. If the circular model of values is correct in suggesting that protection of the environment is viewed in a way that requires transcending one's own interests, then actions pursuing this value may seem subjectively more difficult following activation of competing, selfenhancing motives. This may occur even when there is no real tension between the environmental behavior of interest and selfenhancing motives. For instance, many energy-saving measures are more cost-effective, even if they are automatically seen as an altruistic sacrifice for the welfare of humanity. Our latent motivational assumptions may occasionally get in the way of reframing behaviors to reflect a lack of conflict. Thus, these effects may be a hindrance to campaigns that attempt to elicit behavioral change, and future research could examine ways to address our latent motivational assumptions.

\section{Conclusion}

This research presented important evidence that social values express systemic relations between latent motivations. As a result, changing or priming a particular value has predictable effects on different values and on behaviors that express different values. The precise pattern of these effects can be predicted with the circular model of the motivational conflicts and compatibilities expressed by values, but it would also be interesting to test whether similar predictive power can be achieved by models of motivational interconnections between personal goals and other concepts. Models of motivational interconnections provide a useful complement to theory and research on the processes that guide action.

\section{References}

Alicke, M. D. (1985). Global self-evaluation as determined by the desirability and controllability of trait adjectives. Journal of Personality and Social Psychology, 49, 1621-1630.

Alicke, M. D., Klotz, M. L., Breitenbecher, D. L., Yurak, T. J., \& Vredenburg, D. S. (1995). Personal contact, individuation, and the betterthan-average effect. Journal of Personality and Social Psychology, 68, $804-825$.

Anderson, C., Srivastava, S., Beer, J. S., Spataro, S. E., \& Chatman, J. A (2006). Knowing your place: Self-perceptions of status in face-to-face groups. Journal of Personality and Social Psychology, 91, 1094-1110.

Bardi, A., \& Schwartz, S. H. (2003). Values and behavior: Strength and structure of relations. Personality and Social Psychology Bulletin, 29, 1207-1220

Bargh, J. A. (2006). What have we been priming all these years? On the development, mechanisms, and ecology of nonconscious social behavior. European Journal of Social Psychology, 36, 147-168.

Bargh, J. A., \& Chartrand, T. L. (2000). The mind in the middle: A practical guide to priming and automaticity research. In H. T. Reis \& C. M. Judd (Eds.), Handbook of research methods in social and personality psychology (pp. 253-285). New York: Cambridge University Press.

Bargh, J. A., Gollwitzer, P. M., Lee-Chai, A., Barndollar, K., \& Trotschel, R. (2001). The automated will: Nonconscious activation and pursuit of behavioral goals. Journal of Personality and Social Psychology, 81, 1014-1027.

Bernard, M. M., Maio, G. R., \& Olson, J. M. (2003a). Effects of introspection about reasons for values: Extending research on values-astruisms. Social Cognition, 21, 1-25.

Bernard, M. M., Maio, G. R., \& Olson, J. M. (2003b). The vulnerability of values to attack: Inoculation of values and value-relevant attitudes. Personality and Social Psychology Bulletin, 29, 63-75.

Burgoyne, C. B., \& Lea, S. E. G. (2006, November 17). Money is material. Science, 314, 1091-1092.

Chartrand, T. L., \& Bargh, J. A. (1996). Automatic activation of impression formation and memorization goals: Nonconscious goal priming reproduces effects of explicit task instructions. Journal of Personality and Social Psychology, 71, 464-478.

Chernoff, R. A., \& Davison, G. C. (1999). Values and their relationship to HIV/AIDS risk behavior among late-adolescent and young adult college students. Cognitive Therapy and Research, 23, 453-468.

Cohen, J. (1988). Statistical power analysis for the behavioral sciences. Mahwah, NJ: Erlbaum.

Crandall, C. S., D’Anello, S., Sakalli, N., Lazarus, E., Wieczorkowska, G., \& Feather, N. T. (2001). An attribution-value model of prejudice: Anti-fat attitudes in six nations. Personality and Social Psychology Bulletin, 27, 30-37.

Crandall, C. S., \& Martinez, R. (1996). Culture, ideology, and anti-fat attitudes. Personality and Social Psychology Bulletin, 22, 1165-1176. 
Deci, E. L., \& Ryan, R. M. (2000). The "what" and "why" of goal pursuits: Human needs and the self-determination of behavior. Psychological Inquiry, 11, 227-268.

Devine, P. G., Plant, E. A., \& Buswell, B. N. (2000). Breaking the prejudice habit: Progress and obstacles. In S. Oskamp (Ed.), Reducing prejudice and discrimination (pp. 185-208). Mahwah, NJ: Erlbaum.

Eiser, J. R. (1987). The expression of attitude. New York: Springer-Verlag.

Ferguson, M. J., \& Bargh, J. A. (2004). Liking is for doing: The effect of goal pursuit on automatically activated attitudes. Journal of Personality and Social Psychology, 87, 557-572.

Fishbein, M., \& Ajzen, I. (1981). Acceptance, yielding, and impact: Cognitive processes in persuasion. In R. E. Petty, T. M. Ostrom, \& T. C. Brock (Eds.), Cognitive responses in persuasion (pp. 339-359). Mahwah, NJ: Erlbaum.

Fitzsimons, G. M., \& Bargh, J. A. (2003). Thinking of you: Nonconscious pursuit of interpersonal goals associated with relationship partners. Journal of Personality and Social Psychology, 84, 148-164.

Fitzsimons, G., \& Shah, J. Y. (2008). How goal instrumentality shapes relationship evaluations. Journal of Personality and Social Psychology, 95, 319-337.

Gaertner, S. L., \& Dovidio, J. F. (1986). The aversive form of racism. In S. L. Gaertner \& J. F. Dovidio (Eds.), Prejudice, discrimination, and racism (pp. 61-89). San Diego, CA: Academic Press.

Gaertner, S. L., \& Dovidio, J. F. (2005). Understanding and addressing contemporary racism: From aversive racism to the common ingroup identity model. Journal of Social Issues, 61, 615-639.

Garling, T. (1999). Value priorities, social value orientations and cooperation in social dilemmas. British Journal of Social Psychology, 38, 397-408.

Grouzet, F. M. E., Kasser, T., Ahuvia, A., Dols, J. M. F., Kim, Y., Lau, S., et al. (2005). The structure of goal contents across 15 cultures. Journal of Personality and Social Psychology, 89, 800-816.

Grube, J. W., Chen, M. J., Madden, P., \& Morgan, M. (1995). Predicting adolescent drinking from alcohol expectancy values: A comparison of additive, interactive, and nonlinear models. Journal of Applied Social Psychology, 25, 839-857.

Grube, J. W., Mayton, D. M., II, \& Ball-Rokeach, S. J. (1994). Inducing change in values, attitudes, and behaviors: Belief system theory and the method of value self-confrontation. Journal of Social Issues, 50, 153173.

Herek, G. M. (2000). The psychology of sexual prejudice. Current Directions in Psychological Science, 9, 19-22.

Hertel, G., \& Kerr, N. L. (2001). Priming in-group favoritism: The impact of normative scripts in the minimal group paradigm. Journal of Experimental Social Psychology, 37, 316-324.

Judge, T. A., \& Bretz, R. D. (1992). Effects of work values on job choice decisions. Journal of Applied Psychology, 77, 261-271.

Karremans, J. C. (2007). Considering reasons for a value influences behaviour that expresses related values: An extension of the valueas-truisms hypothesis. European Journal of Social Psychology, 37, $508-523$.

Kasser, T., Koestner, R., \& Lekes, N. (2002). Early family experiences and adult values: A 26-year, prospective longitudinal study. Personality and Social Psychology Bulletin, 28, 826-835.

Kasser, T., \& Ryan, R. M. (1996). Further examining the American dream: Differential correlates of intrinsic and extrinsic goals. Personality and Social Psychology Bulletin, 22, 280-287.

Katz, I., \& Hass, R. G. (1988). Racial ambivalence and American value conflict: Correlational and priming studies of dual cognitive structures. Journal of Personality and Social Psychology, 55, 893-905.

Kitayama, S., Markus, H. R., Matsumoto, H., \& Norasakkunkit, V. (1997). Individual and collective processes in the construction of the self: Self-enhancement in the United States and self-criticism in Japan. Journal of Personality and Social Psychology, 72, 1245-1267.
Kristiansen, C. M., \& Zanna, M. P. (1988). Justifying attitudes by appealing to values: A functional perspective. British Journal of Social Psychology, 27, 247-256.

Kruger, J., \& Dunning, D. (1999). Unskilled and unaware of it: How difficulties in recognizing one's own incompetence lead to inflated self-assessments. Journal of Personality and Social Psychology, 77, 1121-1134.

Kruglanski, A. W., Shah, J. Y., Fishbach, A., Friedman, R., Chun, W. Y., \& Sleeth-Keppler, D. (2002). A theory of goal systems. Advances in Experimental Social Psychology, 34, 331-378.

Kuhnen, U., Hannover, B., \& Schubert, B. (2001). The semanticprocedural interface model of the self: The role of self-knowledge for context-dependent versus context-independent modes of thinking. Journal of Personality and Social Psychology, 80, 397-409.

Lawler, E. J., Thye, S. R., \& Yoon, J. (2000). Emotion and group cohesion in productive exchange. American Journal of Sociology, 106, 616-657.

Macrae, C. N., \& Johnston, L. (1998). Help, I need somebody: Automatic action and inaction. Social Cognition, 16, 400-417.

Maio, G. R., Hahn, U., Frost, J. M., \& Cheung, W. (in press). Applying the value of equality unequally: Effects of value instantiations that vary in typicality. Journal of Personality and Social Psychology.

Maio, G. R., \& Olson, J. M. (1998). Values as truisms: Evidence and implications. Journal of Personality and Social Psychology, 74, 294 311.

Maio, G. R., Olson, J. M., Allen, L., \& Bernard, M. M. (2001). Addressing discrepancies between values and behavior: The motivating effect of reasons. Journal of Experimental Social Psychology, 37, 104-117.

Maio, G. R., Roese, N. J., Seligman, C., \& Katz, A. (1996). Rankings, ratings, and the measurement of values: Evidence for the superior validity of ratings. Basic and Applied Social Psychology, 18, 171-181.

Maio, G. R., Verplanken, B., Manstead, A. S. R., Stroebe, W., Abraham, C. S., Sheeran, P., et al. (2007). Social psychological factors in lifestyle change and their relevance to policy. Journal of Social Issues and Policy Review, 1, 99-137.

Oesterreich, D. (2005). Flight into security: A new approach and measure of the authoritarian personality. Political Psychology, 26, 275-297.

Pakizeh, A., Gebauer, J. E., \& Maio, G. R. (2007). Basic human values: Inter-value structure in memory. Journal of Experimental Social Psychology, 43, 458-465.

Paulhus, D. L. (2002). Socially desirable responding: The evolution of a construct. In H. Braun, D. N. Jackson, \& D. E. Wiley (Eds.), The role of constructs in psychological and educational measurement (pp. 67-88). Mahwah, NJ: Erlbaum.

Paulhus, D. L., \& Reid, D. B. (1991). Enhancement and denial in socially desirable responding. Journal of Personality and Social Psychology, 60, 307-317.

Rees, K. J., \& Maio, G. R. (2007). Social values as self-guides: Value centrality influences regulatory focus and experienced emotion. Manuscript submitted for publication.

Roccas, S., Sagiv, L., Schwartz, S. H., \& Knafo, A. (2002). The Big Five personality factors and personal values. Personality and Social Psychology Bulletin, 29, 789-801.

Rokeach, M. (1973). The nature of human values. New York: Free Press.

Rokeach, M. (1975). Long-term value change initiated by computer feedback. Journal of Personality and Social Psychology, 32, 467-476.

Sagiv, L., \& Schwartz, S. H. (1995). Value priorities and readiness for out-group social contact. Journal of Personality and Social Psychology, 69, 437-448.

Schwartz, S. H. (1992). Universals in the content and structure of values: Theoretical advances and empirical tests in 20 countries. Advances in Experimental Social Psychology, 25, 1-65.

Schwartz, S. H. (1996). Value priorities and behavior: Applying the theory of integrated value systems (Vol. 8). Mahwah, NJ: Erlbaum.

Schwartz, S. H., \& Inbar Saban, N. (1988). Value self-confrontation as a 
method to aid in weight loss. Journal of Personality and Social Psychology, 54, 396-404.

Schwartz, S. H., \& Rubel, T. (2005). Sex differences in value priorities: Cross-cultural and multimethod studies. Journal of Personality and Social Psychology, 89, 1010-1028.

Soder, M. (1990). Prejudice or ambivalence? Attitudes toward persons with disabilities. Disability, Handicap, and Society, 5, 227-241.

Sorrentino, R. M., Nezlek, J. B., Yasunaga, S., Kouhara, S., Otsubo, Y., \& Shuper, P. (2008). Uncertainty orientation and affective experiences: Individual differences within and across cultures. Journal of CrossCultural Psychology, 39, 129-146.

Streib, H. (1999). Off-road religion? A narrative approach to fundamentalist and occult orientations of adolescents. Journal of Adolescence, 22, $255-267$.
Taylor, S. E., \& Lobel, M. (1989). Social comparison activity under threat: Downward evaluation and upward contacts. Psychological Review, 96, $569-575$.

Vohs, K. D., Mead, N. L., \& Goode, M. R. (2006, November 17). The psychological consequences of money. Science, 314, 1154-1156.

Walther, E. (2001). Automatic social behaviour: How does priming of egoism and altruism influence helping behaviour? Zeitschrift Fur Experimentelle Psychologie, 48, 248-257.

Received May 25, 2007

Revision received March 19, 2009

Accepted March 24, 2009

\section{Members of Underrepresented Groups: Reviewers for Journal Manuscripts Wanted}

If you are interested in reviewing manuscripts for APA journals, the APA Publications and Communications Board would like to invite your participation. Manuscript reviewers are vital to the publications process. As a reviewer, you would gain valuable experience in publishing. The P\&C Board is particularly interested in encouraging members of underrepresented groups to participate more in this process.

If you are interested in reviewing manuscripts, please write APA Journals at Reviewers@apa.org. Please note the following important points:

- To be selected as a reviewer, you must have published articles in peer-reviewed journals. The experience of publishing provides a reviewer with the basis for preparing a thorough, objective review.

- To be selected, it is critical to be a regular reader of the five to six empirical journals that are most central to the area or journal for which you would like to review. Current knowledge of recently published research provides a reviewer with the knowledge base to evaluate a new submission within the context of existing research.

- To select the appropriate reviewers for each manuscript, the editor needs detailed information. Please include with your letter your vita. In the letter, please identify which APA journal(s) you are interested in, and describe your area of expertise. Be as specific as possible. For example, "social psychology" is not sufficient-you would need to specify "social cognition" or "attitude change" as well.

- Reviewing a manuscript takes time (1-4 hours per manuscript reviewed). If you are selected to review a manuscript, be prepared to invest the necessary time to evaluate the manuscript thoroughly. 